\title{
Jagriti Narang and Chandra Shekhar Pundir (Eds): Biosensors: An Introductory Textbook
}

\section{Peter Myers ${ }^{1}$}

๑) Springer-Verlag GmbH Germany, part of Springer Nature 2018

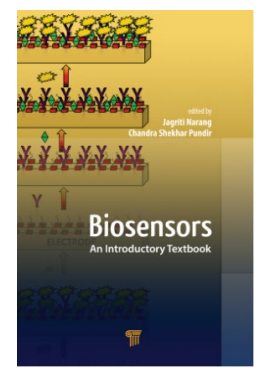

\author{
Bibliography \\ Biosensors: An Introductory Textbook \\ Jagriti Narang, Chandra Shekhar Pundir (Eds) \\ Pan Stanford Publishing, Singapore, 2017, pp 168 \\ ISBN 978-981-4745-94-9 (Hardcover) \\ GBP 48.79, USD 99.95
}

I have now read this book twice as the first time I just could not understand as to what market it was aimed. On my second read, I am even more confused!

The book is a short text of a total of 160 pages and that includes the index. However, if you just concentrate on the chapters that relate to biosensors then it is a book of two chapters. If you include nanoparticles, then there are three chapters. If you need to know about spectroscopic methods and electrochemical techniques, then there are two chapters on these. However, there does not seem to be any relation to the main subject of biosensors. And finally, there is a chapter on microfluidics again that make no attempt to relate microfluidics to biosensors.

Can you see my problem? Why do I need to know about SEM's, TEM's, UV spectroscopy, to gain an introduction to biosensors? Why do I need to know about cyclic and square wave voltammetry? On the first reading, I thought the chapter on the manufacture of nanoparticles might be useful, and maybe, it is to a nanoparticle chemist as it gives a description of different manufacturing methods. However, I thought that this book was about biosensors and not on the manufacture of nanoparticles.

On reading this book, I thought that I would gain some knowledge of biosensors; I did not gain any.

If I were to just concentrate on the two biosensor chapters in the book, all I can say is that you would gain as much information by just reading the abstract of the book provided by the publisher.
Peter Myers

peter.myers@liverpool.ac.uk

1 Department of Chemistry, University of Liverpool,

Liverpool, UK 